\title{
A CHUVA NO ESTADO DE GOIÁS E DISTRITO FEDERAL: ASPECTOS ESPACIAIS, TEMPORAIS E DINÂMICOS
}

\author{
NEVES, Gustavo Zen Figueiredo - gustavozen@usp.br \\ Universidade de São Paulo / USP
}

\begin{abstract}
RESUMO: O objetivo deste trabalho foi compreender a distribuição espaço-temporal das chuvas no Estado de Goiás e o Distrito Federal, e suas principais características qualiquantitativas no período de 1975 a 2015. A metodologia baseou-se no levantamento do referencial teórico-metodológico; obtenção dos dados; espacialização dos postos e de séries temporais consistentes; tratamento estatístico e a identificação de "anos-padrão". Elaborou-se a climatologia das Frentes frias e a representação cartográfica da distribuição das chuvas anuais e sazonais na área de estudo. Os resultados observados apontam para uma variabilidade e irregularidade da distribuição das chuvas entre a região norte de Goiás e valores ligeiramente mais reduzidos no sentido sudoeste do Estado de Goiás. Os mecanismos de precipitação são impostos pela atuação dos sistemas atmosféricos intertropicais. Ressalta-se ainda interação do Planalto Central Brasileiro na participação das chuvas locais ocasionadas pelos efeitos termodinâmicos de superfície e dos aglomerados convectivos locais provocados pela Zona de Convergência do Atlântico Sul.
\end{abstract}

PALAVRAS-CHAVES: Centro-Oeste; Precipitação; Variabilidade; Climatologia.

THE RAIN IN THE STATE OF GOIÁS AND THE FEDERAL DISTRICT: SPACE, TEMPORATIVE AND DIN MICOS

ABSTRACT: The objective of this work was understand the spatial-temporal distribution of rainfall in the State of Goiás and the Federal District, and its main qualitative and quantitative characteristics from 1975 to 2015. The methodology was based on the survey of the theoretical-methodological reference; obtainment the data; spatialization of stations and consistent time series; statistical treatment and the identification of "standard years". The climatology of the cold fronts and the cartographic representation of the annual and seasonal rainfall distribution in the study area were elaborated. The observed results point to a variability and irregularity of the rainfall distribution between the northern region of Goiás and slightly lower values in the southwest direction. Precipitation mechanisms are imposed by the performance of the atmospheric systems equatorials and intertropicals. It is also worth mentioning the interaction of the Brazilian Central Plateau in the participation of the local rains caused by the thermodynamic effects of the surface and of the local convective agglomerates caused by the Convergence Zone of the South Atlantic

KEYWORDS: Midwest; Precipitation; Variability; Climatology.

\section{INTRODUÇÃO}

Os estudos climáticos revelam ainda hoje enormes lacunas no que se refere ao papel da dinâmica atmosférica na gênese e distribuição das chuvas na Região Centro-Oeste do Brasil. Sabe-se que a observação da distribuição das chuvas, durante um longo período, coloca em evidência as irregularidades do ritmo climático, pois permite constatar períodos muito chuvosos revezando-se com outros de severa estiagem. Tal distribuição deve ser analisada sob os aspectos quantitativo (diferentes volumes de precipitação) e qualitativo (padrões de distribuição pluviométrica e respectivos ritmos), sendo de suma importância para a explicação da natureza e cadência das atividades humanas Zavattini (1990, p. 12). 
A chuva é um dos elementos climáticos mais importantes no que se refere à sobrevivência da sociedade humana, pois um dos fatores mais essenciais para manutenção da nossa sociedade, a produção de alimentos, está intimamente relacionado com distribuição espacial e temporal das chuvas. Além disso, as populações humanas podem experimentar situações variadas no que se refere à disponibilidade e distribuição das chuvas (secas e enchentes) que interferem e influenciam na organização espacial.

As pesquisas climatológicas no Brasil têm como base a considerável contribuição de Monteiro (1962, 1963a, 1964, 1969, 1971, 2000) à Climatologia Geográfica Brasileira. Entretanto, os diversos estudos climáticos que têm sido realizados nas últimas décadas, principalmente aqueles relacionados às chuvas tem se concentrado apenas em algumas das regiões brasileiras, principalmente no Sul, Sudeste e Nordeste (ZAVATTINI, 1990).

O processo de ocupação do Centro-Oeste, acelerado a partir da década de 1960 com a construção de Brasília e a implantação de rodovias, o crescente interesse agrícola pelo "cerrado" desde os anos 1970, a divisão do estado de Goiás e Tocantins e a maior dinamização econômica da chamada "marcha para oeste" trouxeram uma agressão ao ambiente, tornando fundamental o conhecimento de seus fatores naturais e antrópicos. Frequentemente, ele também se ocupa dos fatos climáticos correlatos (enchentes, estiagens, chuvas torrenciais, geadas), com destaque para as chuvas e suas implicações nas atividades humanas.

O Distrito Federal e, principalmente, o Estado de Goiás destacam-se no cenário agropecuário nacional e internacional pela alta capacidade de produção agrícola. A região é líder na produção graneleira nacional, sendo responsável por 45\% da produção nacional em 2012 (CAVALCANTI, et al, 2014). Sua localização geográfica é estratégica do ponto de vista geopolítico para integração interestadual. É considerada como o eixo de integração entre as demais regiões políticas e administrativas da Federação.

Essas demandas e necessidades atreladas aos ramos econômicos, agropecuários, comércio, serviços e crescimento da população urbana conduzem a uma maior aproximação desses setores com institutos de pesquisa e ensino. Torna-se urgente o estímulo de novos estudos para regiões tropicais brasileiras, alicerçados sobre o planalto central brasileiro que congrega o frágil bioma de cerrado e divisor de três grandes regiões hidrográficas da América do Sul: Rio Paraná, Rio São Francisco e Rios Araguaia e Tocantins. O objetivo deste trabalho é de apresentar algumas considerações sobre as características pluviométricas do Estado de Goiás e Distrito Federal alicerçados na climatologia dinâmica.

\section{CARACTERÍSTICAS PLUVIOMÉTRICAS: SÍNTESE DOS ESTUDOS REALIZADOS}

Com relação à distribuição pluviométrica, existem diversos estudos de organizações federais e estaduais que mapearam as chuvas no centro-oeste do Brasil, sobretudo o Estado de Goiás e Distrito Federal. Destacamos alguns desses trabalhos a seguir.

O Instituto Nacional de Meteorologia publicou no ano de 2015 o mapeamento das chuvas em todo o território nacional, seguindo as Normais 
Climatológicas para o período de 1961 a 1990. A posição geográfica da referida localidade de estudo sob o efeito continental, a geomorfologia e a imposição da circulação atmosférica regional, inferem uma diversidade significativa ao regime de chuvas em toda a região de Goiás e Distrito Federal. Contudo, é importante destacar que na metodologia do trabalho apresentado foram utilizadas apenas doze estações automáticas ou postos pluviométricos, localizados principalmente nas porções Leste, Sul e Central do Estado de Goiás e Distrito Federal (INMET, 2015).

A Secretaria de Planejamento do Estado de Goiás (SEGPLAN, 2014), elaborou o Atlas do Estado de Goiás que contém as médias pluviométricas para todo o Estado. Porém, o documento não ilustra as metodologias adotadas com relação à quantidade de postos pluviométricos e as ferramentas metodológicas para a síntese do mapa da distribuição de chuvas.

O Serviço Geológico do Brasil - Companhia de Pesquisa de Recursos Minerais (CPRM) publicou, em 2010, o Atlas Pluviométrico do Brasil, com ilustrações quantitativas anuais da distribuição de chuvas em todo o território nacional, no período de 1977 a 2006. Este, nos parece o mais fidedigno estudo pluviométrico no que tange a distrbuição dos postos pluviométricos e a série histórica. Contudo, da mesma maneira que a SEGPLAN (2014), o Atlas não apresenta a metodologia que alicerçou a pesquisa.

No contexto acadêmico, diversas teses e dissertações foram realizadas nas últimas décadas com diferentes objetivos. Devido o limitado espaço neste capítulo, tecemos alguns desses trabalhos de forma sintética: compreender a produção agrícola do sudoeste Goiano (MARIANO, 2005); identificar os sistemas sinópticos tropicais da América do Sul (VIRGI, 1981; CAVALCANTI, 1982; QUADRO e ABREU, 1994); analisar variabilidade, tendências e séries estatísticas termo-pluviométricas para Goiás e Distrito Federal ou regiões hidrográficas do Paraná, Tocantins e Araguaia (STEINKE, 2004; MESQUITA et al, 2009; ALVES e VECCHIA, 2011; COSTA et al, 2012; PENEREIRO et al, 2015; NASCIMENTO et al, 2015; NASCIMENTO et al, 2017).

Com isso, ilustramos alguns referenciais bibliográficos sobre a caracterização e distribuição das chuvas em diferentes escalas, seja ela nacional, ou propriamente a delimitação do Estado Goiano e Distrito Federal com adoção de diferentes metodologias e resultados para a mesma região em destaque.

\section{MATERIAIS E MÉTODOS}

\section{RECORTE ESPACIAL}

Utilizou-se como critério para a escolha dos postos a distribuição espacial em quadrículas de $1^{\circ} 5^{\prime} \times 1^{\circ} 5^{\prime}$ (Latitude por Longitude), num mapa de escala de 1:250.000 (Figura 1), totalizando quarenta quadrículas recobrindo toda a área de estudo do Estado de Goiás e Distrito Federal. Tal medida foi tomada tendo em vista o fato de que a área de estudo é extensa e que a divisão em quadrículas facilitaria a análise por setores ou parcelas menores de áreas. 


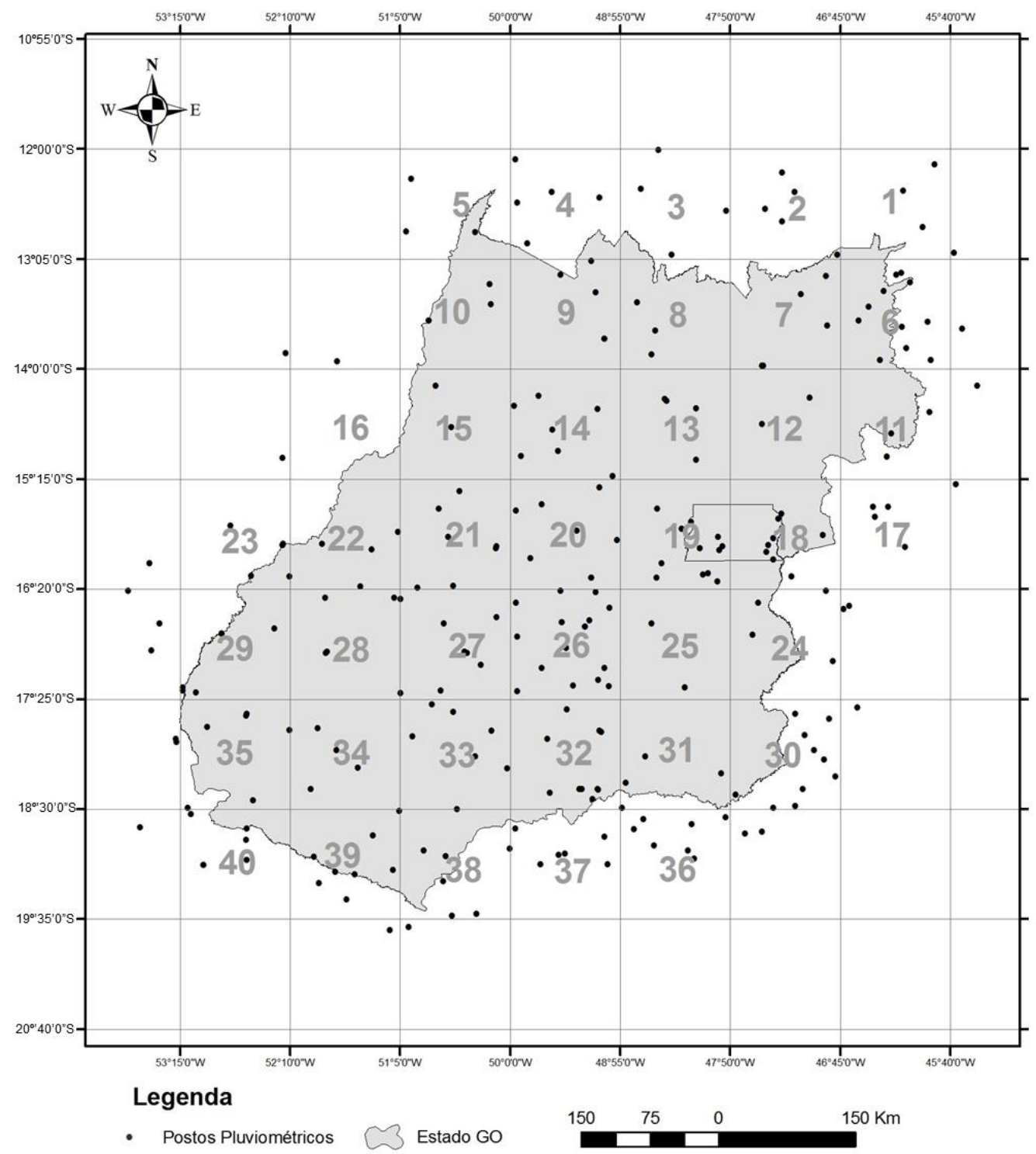

Figura 1 - Distribuição das quadrículas e estações pluviométricas no Estado de Goiás e Distrito Federal. Fonte: ANA/SNIRH/Hidro-Web (2017). Elaboração: O autor (2018).

\section{OBTENÇÃO DOS DADOS E A DEFINIÇÃO DA SÉRIE TEMPORAL}

A série histórica utilizada para a análise climatológica foi escolhida a partir da disponibilidade de dados pluviométricos no Sistema Nacional de Informações de Recursos Hídricos (SNIRH/HidroWeb), plataforma eletrônica da Agência Nacional de Águas - ANA.

Para a escolha do melhor posto em cada quadrícula, foram adotados os seguintes critérios: a) Priorizou-se, em cada quadrícula, o posto pluviométrico com série temporal com o menor número de lacunas (ou falhas nos dados) e que se situe mais ao centro da área; 
b) Preencheu-se as lacunas existentes, substituindo-as com dados equivalentes de outros postos dentro da mesma quadrícula, independente da distância que se encontram um do outro e da posição que ocupam naquela quadrícula.

O período com séries históricas mais satisfatórias, ou seja, com menos falhas, compreende a data posterior o ano de 1975. Portanto, o presente estudo apresenta uma série histórica pluviométrica entre 1 de janeiro de 1975 a 31 de dezembro de 2015, totalizando 41 anos.

Todo o arranjo, verificação e escolha dos melhores postos com dados diários de chuvas, bem com a análise e seleção da série histórica e o tratamento estatístico dos dados de chuva referentes à série temporal definida para esta pesquisa foram realizados no software Excel 2007 e em ambiente SIG (Sistemas de Informação Geográfica), por meio de planilhas minuciosamente elaboradas, além da confecção dos gráficos, tabelas e planilhas, todos muito úteis para a síntese e interpretação dos resultados.

\section{IDENTIFICAÇÃO DE "ANOS-PADRÃO"}

O "ano-padrão" foi definido a partir da observação dos totais anuais da precipitação e suas variabilidades espaço-temporais. Assim, o ano em que a maioria das quadrículas apresentaram totais anuais próximos à média calculada, foi classificada como ano padrão habitual Monteiro (1973) e Sant'Anna Neto (1990).

Combinando os totais de chuva do período da série histórica entre 1975 e 2015 os intervalos sugeridos estatisticamente foram escalonados com o auxílio de cores (tons de verde para valores frequentes / "anos habituais"; tons de azul para valores elevados / "anos chuvosos"; vermelho e amarelo para valores baixos ( "anos secos"), com a organização das séries históricas para as 40 quadrículas da área de estudo.

A seguir, ilustra-se os intervalos de classe para a definição dos anospadrão (Figura 2). 


\begin{tabular}{|c|c|c|}
\hline Classificação & Padrões Pluviométricos & Intervalos de Classe \\
\hline \multirow{4}{*}{ Ano Seco } & Extremamente Seco & $<-30,01 \%$ \\
\cline { 2 - 3 } & Muito Seco & $-30 \mid-25,01 \%$ \\
\cline { 2 - 3 } & Seco & $-25 \mid-20,01 \%$ \\
\cline { 2 - 3 } & Seco & $-20 \mid-15,01 \%$ \\
\cline { 2 - 3 } & Tendente a Seco & $-15 \mid-10,01 \%$ \\
\hline \multirow{3}{*}{ Ano Normal } & Habitual Levemente Seco & $-10 \mid-5,01 \%$ \\
\cline { 2 - 3 } & Habitual & $-5 \mid-0,01 \%$ \\
\cline { 2 - 3 } & Habitual Levemente Chuvoso & $0 \mid 5 \%$ \\
\hline \multirow{3}{*}{ Ano Chuvoso } & Tendente a Chuvoso & $\mathbf{5 , 0 1 | 1 0 \%}$ \\
\cline { 2 - 3 } & Chuvoso & $10,01 \mid 15 \%$ \\
\cline { 2 - 3 } & Chuvoso & $20,01 \mid 25 \%$ \\
\cline { 2 - 3 } & Muito Chuvoso & $25,01 \mid 30 \%$ \\
\cline { 2 - 3 } & Extremamente Chuvoso & $>30,01 \%$ \\
\hline
\end{tabular}

Figura 2 - Limites do Coeficiente de Variação com vistas à definição dos anos padrão. Ano Seco: precipitação extemamente reduzida; Ano Habitual: Pluviosidade normal dentro do desvio médio padronizado; Ano Chuvoso: Pluviosidade excepcionalmente elevada. Adaptado de Sant'Anna Neto (1990). Elaboração: O autor (2018).

\section{CATALOGAÇÃo PRELIMINAR DOS SISTEMAS ATMOSFÉRICOS}

Por meio das cartas de superfície ao nível do mar e as cartas sinópticas, fornecidas respectivamente pelo Centro de Hidrografia (Marinha do Brasil) e o Centro de Previsão do Tempo e Estudos Climáticos (CPTEC/INPE), foram identificados e catalogados os centros de ação dos sistemas atmosféricos que atuaram na área de estudo.

A metodologia empregada sustenta-se da observação diária das cartas sinópticas, o monitoramento dos campos de pressão atmosférica e os avanços da linha cartográfica de "Frente Fria" que percorreram ou terminam seu ciclo migratório sobre a referida área de estudo, contabilizando apenas um vetor para cada sistema frontal, entre 1/1/1975 a 31/12/2015. Neste artigo, apresenta-se os avanços frontais de um ano excepcionalmente chuvoso e a tabulação de onze anos de observação. Outras informações estão bem documentadas em Neves (2018).

\section{RESULTADOS E DISCUSSÕES \\ INVENTÁRIO DAS ESTAÇÕES PLUVIOMÉTRICAS NA ÁREA DE ESTUDO}

No que tange a distribuição de postos pluviométricos automáticos e convencionais, a rede de aparelhos é mais densa, porém não distribuida de maneira uniforme e planejada sobre o território em questão. No levantamento e quantificação dos postos pluviométricos, ao longo de várias décadas, observamos que a Agência Nacional de Águas (ANA) reúne aproximadamente 230 postos no Estado de Goiás e Distrito Federal (Figura 3). 


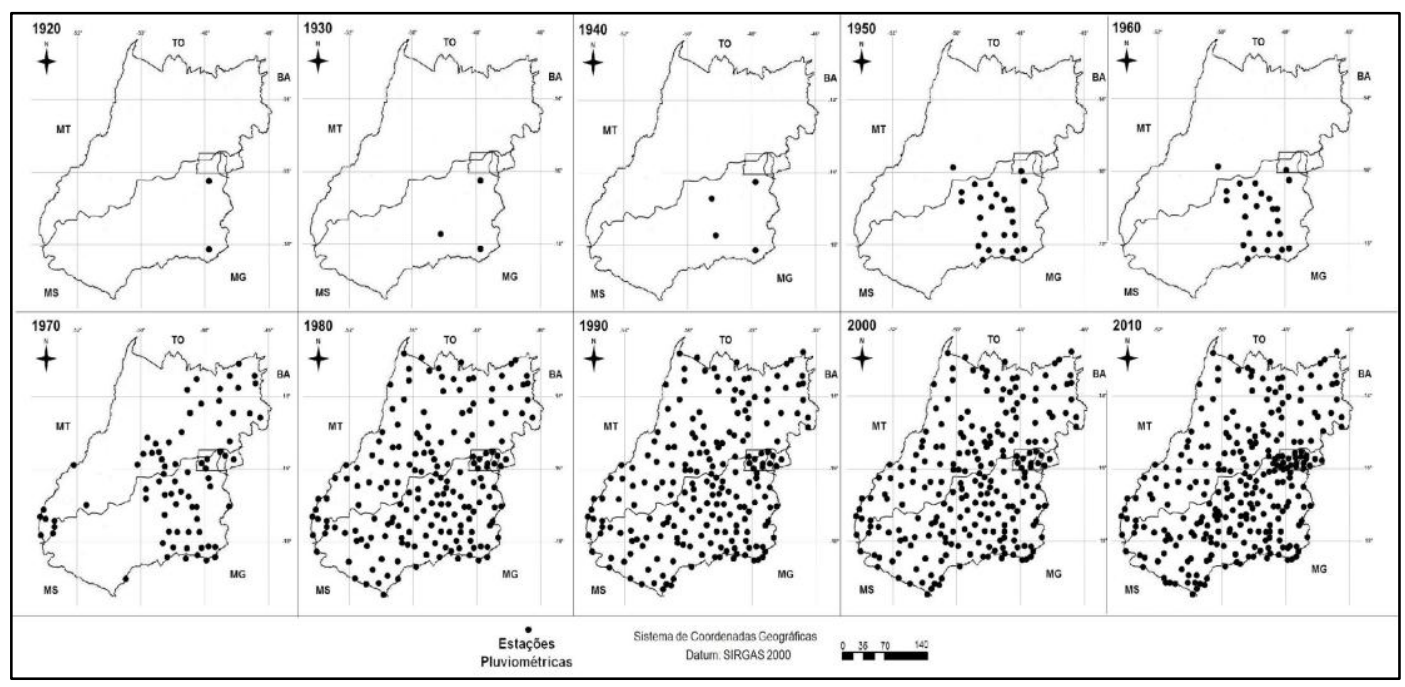

Figura 3- Distribuição das estações pluviométricas no Estado de Goiás e Distrito Federal. Fonte: ANA (2013). Elaboração: O autor (2018).

Nota-se uma evolução da quantidade de postos pluviométricos a partir da década de 1970 que se estende até a década de 2010 (ANA, 2013), sobretudo no eixo de expansão e aglomeração populacional no centro-sul do Estado de Goiás e as cidades adjacentes da capital Federal. Todavia, a qualidade das informações encontrada é baixa, muitas vezes sem a disponilidade das séries históricas nos sistemas eletrônicos do Sistema Nacional de Informações de Recursos Hídricos (SNIRH/HidroWeb), e também apresentam dados faltantes em seguidos semestres e anos.

Desta forma, o inventário apresentado pelas agências e organizações estaduais e federais revelam a desproporção espacial das estações automáticas, convencionais e dos postos pluviométricos alocados nos grandes centros urbanos e adjacências, sobretudo no Distrito Federal.

\section{SÍNTESE DOS ANOS-PADRÃO}

Apresenta-se de maneira resumida a definição dos anos padrões secos, habituais e chuvosos para as quarenta quadrículas entre os anos de 1975 e 2015. Para a compreensão da Figura 4, recomenda-se observar a Figura 1, que ilustra a sequência das quadrículas dispostas da esquerda para à direita, distribuídas espacialmente em $1^{0} 5^{\prime} \times 1^{\circ} 5^{\prime}$ (Latitude e Longitude) sobre 0 Estado de Goiás e o Distrito Federal.

As colunas representam as quadrículas (da esquerda para a direita Q1 a Q40), e as linhas ilustram os anos, em intervalos de classe de precipitação (da primeira à última linha: 1975 até 2015).

Observa-se que a variação pluviométrica, dentro dos intervalos de classe estabelecidos, é bastante irregular, mas que algumas cores (ou padrões) são frequentemente repetidas em alguns anos. Destaca-se o ano de 1983 como o "ano padrão chuvoso" em grande parte das quadrículas; os anos de 1990 e Ano 15 - Edição Especial - XIII Simpósio Brasileiro de Climatologia Geográfica - JUN 2019 
2015 como o "ano excepcionalmente seco", e o ano de 1995 representa mais regularmente a distribuição das chuvas na maior parte quadrículas, sendo o "ano habitual".

A partir da coluna Q19, a frequência de cores no intervalo de classe "habitual" (Figura 2) é mais recorrente. Em síntese, as quadrículas dispostas espacialmente nas porções Central e Sul do Estado de Goiás são providas de chuvas regulares durante alguns meses do ano, quando comparadas com as regiões de latitudes menores. Apesar de os intervalos de extremos negativos serem menos frequentes, há várias colunas que reforçam as irregularidades pluviométricas nas porções ao sul do Estado (Figura 4).

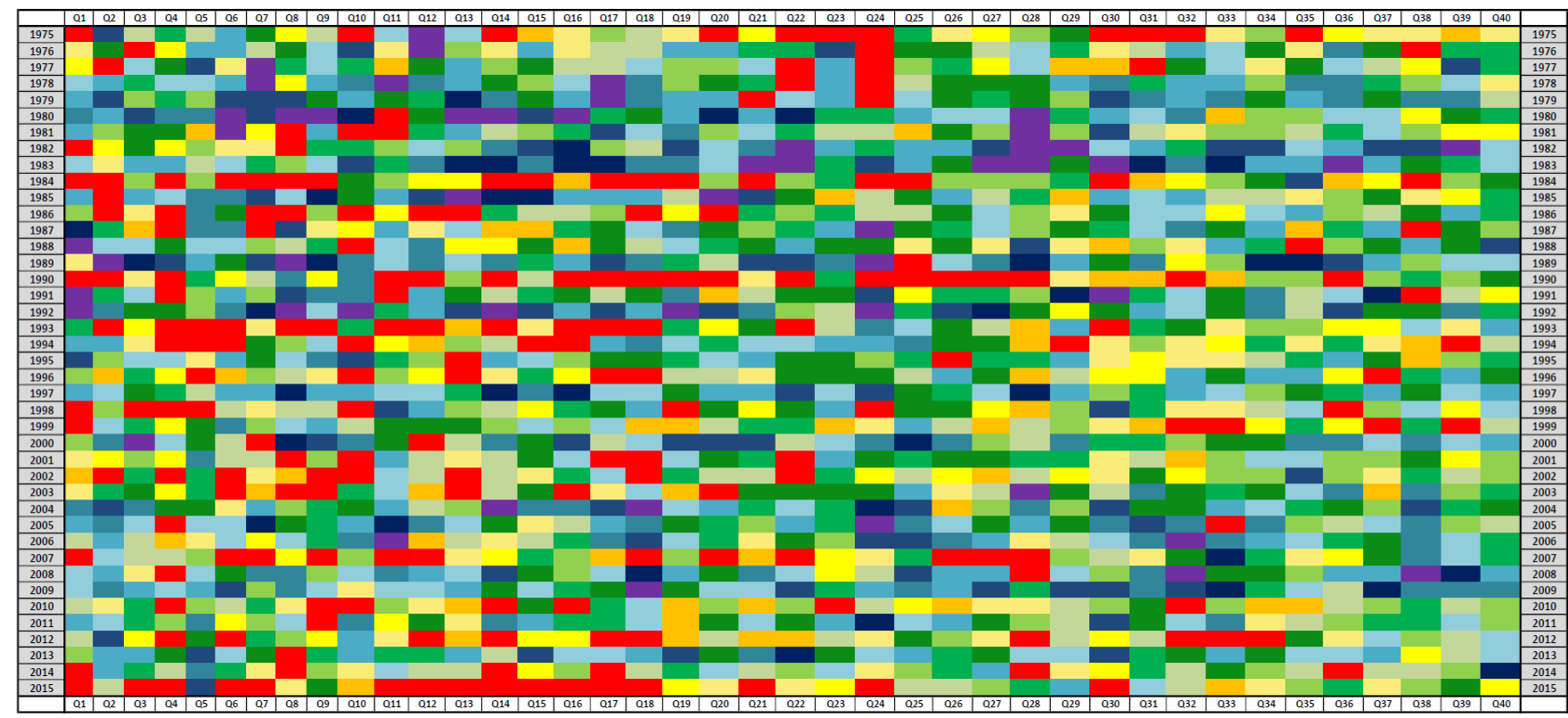

\begin{tabular}{|c|c|c|}
\hline Classificação & Padrões Pluviométricos & Intervalos de Classe \\
\hline \multirow{4}{*}{ Ano Seco } & Extremamente Seco & $<-30,01 \%$ \\
\cline { 2 - 3 } & Muito Seco & $-30 \mid-25,01 \%$ \\
\cline { 2 - 3 } & Seco & $-25 \mid-20,01 \%$ \\
\cline { 2 - 3 } & Seco & $-20 \mid-15,01 \%$ \\
\cline { 2 - 3 } Ano Normal & Tendente a Seco & $-15 \mid-10,01 \%$ \\
\cline { 2 - 3 } & Habitual Levemente Seco & $-10 \mid-5,01 \%$ \\
\cline { 2 - 3 } & Habitual & $-5 \mid-0,01 \%$ \\
\cline { 2 - 3 } & Habitual & $0 \mid 5 \%$ \\
\hline \multirow{3}{*}{ Ano Chuvoso } & $5,01 \mid 10 \%$ \\
\cline { 2 - 3 } & Habitual Levemente Chuvoso & $10,01 \mid 15 \%$ \\
\cline { 2 - 3 } & Tendente a Chuvoso & $15,01 \mid 20 \%$ \\
\cline { 2 - 3 } & Chuvoso & $20,01 \mid 25 \%$ \\
\cline { 2 - 3 } & Chuvoso & $25,01 \mid 30 \%$ \\
\cline { 2 - 3 } & Muito Chuvoso & $>30,01 \%$ \\
\hline
\end{tabular}

Figura 4 - Distribuição dos coeficientes de variação no período de 1975-2015 no Estado de Goiás e Distrito Federal. Fonte: ANA (2013). Elaboração: O autor (2018).

\section{SISTEMAS ATMOSFÉRICOS FRONTAIS: 1975 ATÉ 1985}

Com o objetivo de identificar a gênese das chuvas no Estado de Goiás e Distrito Federal, buscou-se analisar as áreas de atuação dos sistemas atmosféricos por meio de imagens de satélite, cartas sinópticas, as cartas de pressão ao nível do mar e os boletins mensais do Climanálise (CPTEC/INPE).

Ano 15 - Edição Especial - XIII Simpósio Brasileiro de Climatologia Geográfica - JUN 2019 
Muitas informações não estão dispostas de maneira digital ou eletrônica na internet. Houve uma extensa investigação na busca de tais dados, sobretudo anteriores o ano de 1995, nos principais centros e instituições federais que coordenam e armazenam tais informações.

A catalogação dos centros de atuação dos sistemas atmosféricos no Centro-Oeste do Brasil, com especial atenção ao Estado de Goiás e Distrito Federal, visa estabelecer espacialmente as áreas de maior e menor frequência, ou periodicidade de atuação, durante o ano (mensalmente e sazonalmente), principalmente aqueles elegidos como habituais e irregulares secos e chuvosos.

Ilustra-se, na Figura 5, a sobreposição da linha cartográfica "Frente Fria" que percorreu ou terminou seu ciclo migratório dinâmico sobre o Estado de Goiás e o Distrito Federal durante o ano de 1983, somando vinte e sete linhas frontais. O mesmo foi elegido como excepcionalmente chuvoso segundo os critérios adotados de "anos-padrão", Monteiro (1973) e Sant'Anna Neto (1990).

Observa-se que a trajetória preferencial das linhas de Frente Fria, se posiciona nas regiões Sudoeste-Sul-Leste do Estado de Goiás e o Distrito Federal, com orientação Noroeste-Sudeste. É notável que as linhas frontais alcancem o Planalto Central Brasileiro, mais especificamente no setor do Distrito Federal e adjacências geomorfológicas mais elevadas.

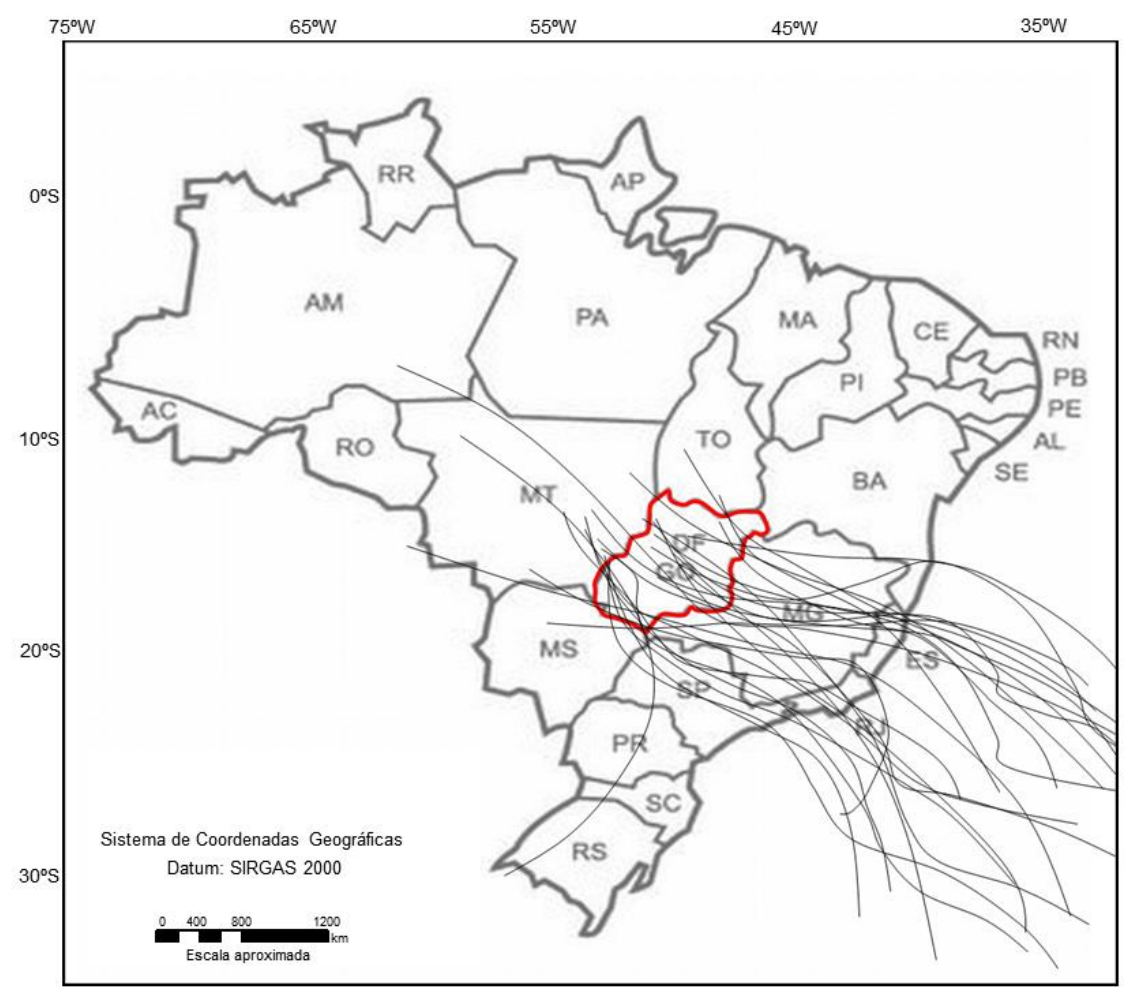

Figura 5 - Catalogação das linhas de Frentes Frias identificadas nas cartas de pressão ao nível do mar (com destaque para o Estado de Goiás e Distrito Federal), "ano-padrão chuvoso" de 1983. Fonte: Centro de Hidrografia e Navegação da Marinha do Brasil. Elaboração: O autor (2018). 
Existem indicativos de que as compartimentações geomorfológicas locais e regionais podem impor condições peculiares aos avanços e limites das Frentes Frias (nas trajetórias latitudinais). A constatação corrobora com as afirmações de Monteiro (1963b), Zavattini (1990) e Marcel Leroux (2005), em que os centros de ação de alta pressão, de ar frio e denso, tomam trajetórias continentais preferenciais pelas formas do relevo, entre outros fatores.

Não obstante, é preciso analisar as compartimentações individualizadas por meio de outros elementos climáticos das estações de superfície, como a temperatura, a direção e velocidade dos ventos e, neste caso específico, as chuvas. Os apontamentos descritos são preliminares e não conclusórios, pois tão importante às inquietações sobre as trajetórias preferenciais dos sistemas atmosféricos é a imposição das barreiras geomorfológicas em relevar se as invasões polares que perpassam as menores latitudes, se traduzem em precipitações, em diferentes intensidades e durações.

A seguir, destacam-se os onze primeiros anos de catalogação das linhas cartográficas de Frente Fria que se deslocaram ou findaram seu ciclo migratório sobre o Estado de Goiás e Distrito Federal. Destacam-se os anos de 1975, 1977 e 1983 com os registros mais elevados da passagem de Frente Fria, contabilizando 25, 23 e 27, respectivamente. Outrora, os anos de 1979 e 1984 obtiveram os menores acumulados catalogados, com valores de 18 e 17 Frentes Frias, respectivamente (Tabela 1 ).

\begin{tabular}{|c|c|c|c|c|c|c|c|c|c|c|c|c|}
\hline $\begin{array}{c}\text { Mês/A } \\
\text { no }\end{array}$ & 1975 & 1976 & 1977 & 1978 & 1979 & 1980 & 1981 & 1982 & 1983 & 1984 & 1985 & $\begin{array}{c}\text { Méd } \\
\text { ia }\end{array}$ \\
\hline Jan & 2 & 1 & 1 & 2 & 2 & 1 & 1 & 2 & 1 & 0 & 2 & 1,4 \\
\hline Fev & 1 & 1 & 1 & 1 & 0 & 1 & 0 & 0 & 2 & 0 & 1 & 0,7 \\
\hline Mar & 1 & 0 & 2 & 2 & 0 & 0 & 1 & 1 & 2 & 0 & 0 & 0,8 \\
\hline Abr & 2 & 2 & 3 & 2 & 1 & 1 & 2 & 2 & 2 & 3 & 2 & 2,0 \\
\hline Mai & 2 & 2 & 2 & 1 & 2 & 1 & 0 & 3 & 3 & 1 & 2 & 1,7 \\
\hline Jun & 3 & 2 & 1 & 1 & 1 & 2 & 3 & 1 & 3 & 1 & 1 & 1,7 \\
\hline Jul & 3 & 2 & 1 & 1 & 2 & 2 & 1 & 3 & 2 & 3 & 0 & 1,8 \\
\hline Ago & 1 & 2 & 1 & 1 & 1 & 3 & 2 & 2 & 2 & 3 & 3 & 1,9 \\
\hline Set & 0 & 2 & 4 & 4 & 3 & 2 & 2 & 2 & 3 & 1 & 2 & 2,3 \\
\hline Out & 5 & 2 & 4 & 4 & 1 & 1 & 2 & 2 & 3 & 1 & 1 & 2,4 \\
\hline Nov & 3 & 3 & 2 & 2 & 3 & 2 & 3 & 2 & 2 & 1 & 3 & 2,4 \\
\hline Dez & 2 & 3 & 1 & 1 & 2 & 3 & 2 & 2 & 2 & 3 & 2 & 2,1 \\
\hline Total & 25 & 22 & 23 & 22 & 18 & 19 & 19 & 22 & 27 & 17 & 19 & 21 \\
\hline
\end{tabular}

Tabela 1 - Totais acumulados de linhas de Frente Fria sobre Goiás e Distrito Federal Síntese 1975/1985. Fonte: Centro de Hidrografia e Navegação da Marinha do Brasil. Elaboração: O autor (2018). 


\section{DISTRIBUIÇÃO DAS CHUVAS EM GOIÁS E DISTRITO FEDERAL}

Apresenta-se os valores médios mensais pluviométricos para a série temporal de 41 anos estudados em todas as quarenta quadrículas. A representação escalar em milímetros de chuva está graduada de 0 a $400 \mathrm{~mm}$ (todos os gráficos na mesma escala de valores), de acordo com a Figura 6.

Observa-se que as médias pluviométricas mensais mais expressivas se localizam na porção norte do Estado de Goiás. Na quadrícula 8, próximo ao Município de Campinaçú e adjacências do Lago Serra da Mesa, os valores de chuva superam os $400 \mathrm{~mm}$ entre os meses de dezembro, janeiro e fevereiro. Ainda, no período chuvoso a sazonalidade média da chuva supera os $300 \mathrm{~mm}$. Todavia, no período seco, as médias mensais não superam $30 \mathrm{~mm}$ nos meses de junho, julho e agosto. Nos meses de transição de períodos chuvosos e secos, existe a ocorrência de acumulados médios de chuva consideráveis para o norte do Estado de Goiás, superando $100 \mathrm{~mm}$. A quadrícula 14, no Município de Pilar de Goiás, também nas adjacências do lago Serra da Mesa, a variação mensal pluviométrica para os 41 anos analisados é semelhante à quadrícula 8, com siginificativos acumulados de chuva no período de verão.

Por outro lado, a quadrícula 5, no extremo Noroeste do Estado de Goiás, situada próximo do Município de São Miguel do Araguaia, os registros médios mensais da série temporal revelaram os menores valores pluviométricos. Os acumulados de chuva superam timidamente a ordem de $100 \mathrm{~mm}$ no quadrimestre mais chuvoso, entre novembro a fevereiro. Porém, a distribuição média mensal é mais homogênea quando comparada com as demais quadrículas, e não apresenta mêses sem chuvas no período de inverno.

As quadrículas, do extremo Nordeste da região de estudo Q6, Q11 e Q17 apresentam um comportamento bastante semelhante. Mas, a quadrícula 1 é singular, apresentando acumulados mensais elevados no período de primaveraverão com o mês de julho historicamente seco e chuvas escassas.

A quadrícula 12, situada na região de maior altitude do Estado de Goiás, nas proximidades do Município de Alto Paraíso de Goiás e do Parque Nacional da Chapada dos Veadeiros, possui valores de chuvas modestos para uma compartimentação geomorfológica que supera 1800 de altitude. Contudo, devese considerar a baixa latitude que se localiza a referida região, sobretudo por se tratar de valores médios analisados em quarenta e um anos.

Toda a porção Oeste do Estado de Goiás nos cursos alto e médio do Rio Araguaia, onde as chuvas de primavera-verão são abundantes e superam $300 \mathrm{~mm}$ seguramente, sem o predomínio de mês seco, na média analisada.

Destaca-se também o extremo sul do Estado de Goiás, limítrofe aos Estados de Mato Grosso do Sul e Minas Gerais. Observa-se que a quadrícula 40 apresenta valores bastante consideráveis de chuva no semestre entre outubro a março, notável para uma região de gradientes altimétricos pouco expressivos e distante significativamente dos centros de ação da Massa Tropical Atlântica. Possivelmente, a ação dos sistemas atmosféricos equatoriais (primavera-verão) e polares (inverno) seja mais proeminente. 


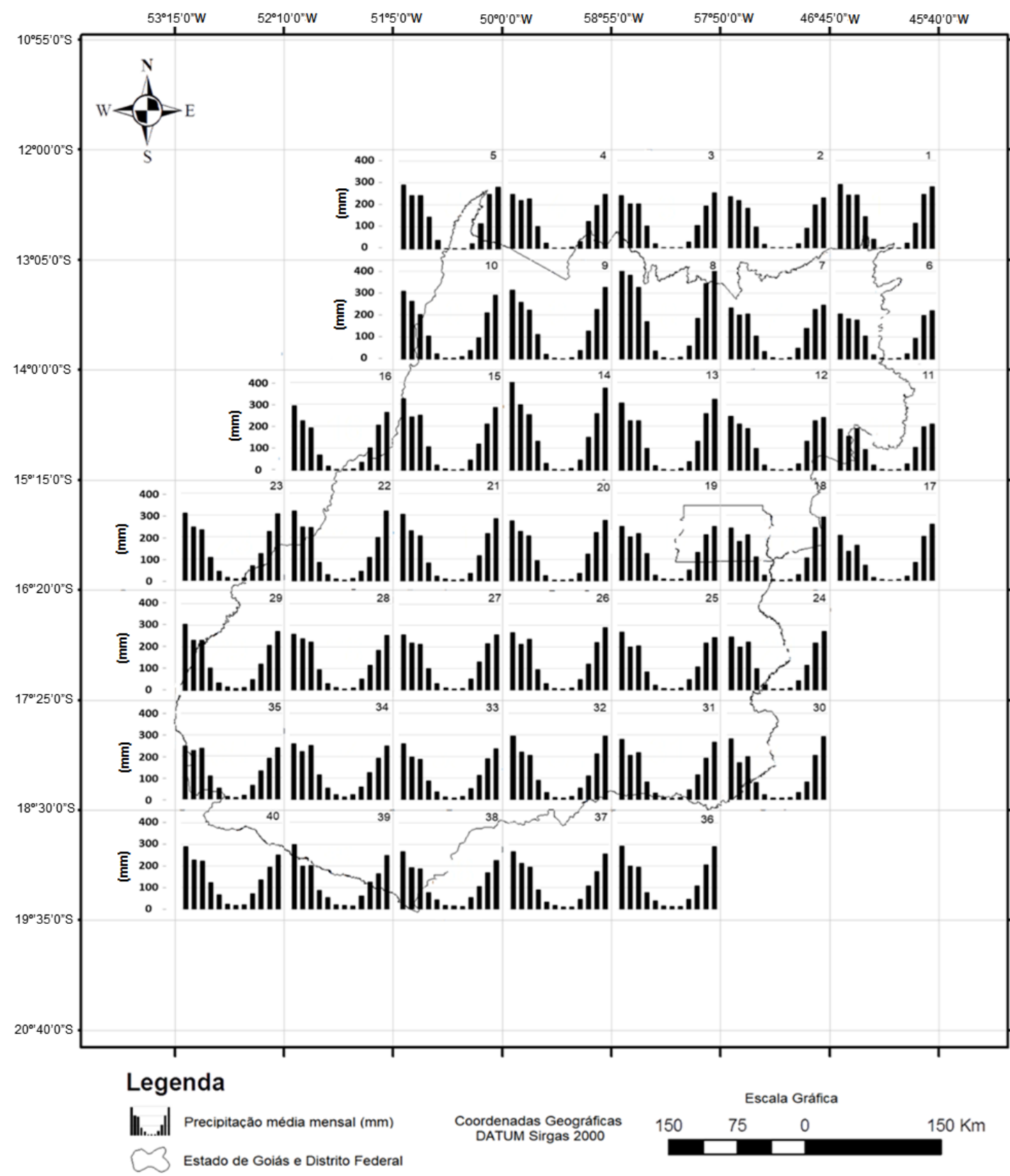

Figura 6 - Precipitação média mensal de 41 anos para o Estado de Goiás e Distrito Federal. Fonte: Agência Nacional de Águas - SNIRH/HidroWeb. Elaboração: Elaboração: O autor (2018).

\section{CONCLUSÕES}

Neste artigo, apresentou-se de forma resumida, as informações sobre o paronama climático do Estado de Goiás e o Distrito Federal, cuja carência de estudos de ordem regional é notória, pela imensa ausência de dados pluviométricos e as irregularidades apresentadas nas séries históricas longas. 
A região Centro-Oeste do Brasil apresenta um grande vazio do ponto de vista da climatologia dinâmica em plena década de 2010-2020, pois há pouquíssimas e privilegiadas estações meteorológicas com séries históricas consistentes em um banco de dados que suporte a quantidade de informações, que muitas vezes sua interface não é amigável para aquisição, tratamento e análise dos dados.

Os postos pluviométricos e a rede meteorológica de superfície são fundamentais para a compreensão do tempo e do clima em escala local e regional, pois quanto mais qualificada for a rede de informações, a robustês dos equipamentos, sensores e sua plena disponibilidade de acesso público, mais efetiva será a justificativa da operacionalização desses dados com vistas ao planejamento presente e futuro (Neves, et al, 2017).

O recorte espacial e temporal empregado neste trabalho é desafiador, principalmente pelo revestimento de base genética que norteia a distribuição geográfica das chuvas. Releva-se pela validade do tratamento dos dados em ambiente de sistemas de informações geográficas para gerenciamento de grandes volumes de informações e a adoção de metodologias consolidadas da Escola Brasileira de Climatologia.

Espera-se assim, contribuir e abrir caminhos para os investigadores e futuros profissionais que necessitam de informações elementares sobre os regimes climáticos do Centro-Oeste do Brasil, região ímpar do frágil bioma de cerrado, berço de grandes bacias hidrográficas, que congrega um futuro promissor na produção graneleira nacional e internacional.

\section{AGRADECIMENTOS}

Ao Conselho Nacional de Desenvolvimento Científico e Tecnológico (CNPq), Processo 140338/2017-9, pelo auxílio financeiro.

\section{REFERÊNCIAS BIBLIOGRÁFICAS}

ALVES, E. D. L. VECCHIA, F. Análise de diferentes métodos de interpolação para a precipitação pluvial no Estado de Goiás. Acta Sciencitarium. Maringá, v.33, n.2, p.193-197, 2011.

ANA - Agência Nacional de Águas. Sistema de Informações Hidrológicas. Disponível em: <http://www.ana.gov.br/mapainicial/pgMapaL.asp>. Acesso em: 10 jun. 2015.

ANA - Agência Nacional de Águas. Evolução da Rede Hidrometeorológica na Região Hidrográfica do Tocantins Araguaia, São Francisco e Paraná. Texto disponível

em: <http://arquivos.ana.gov.br/infohidrologicas/rhtocantinsaraguaia.pdf>. Acesso em: 10 jan. 2013.

CAVALCANTI, I. A. Um estudo sobre as interações entre os sistemas de circulação de escala sinótica e circulações locais. INPE 2494 TDL/097. 1982.

CAVALCANTI, I. M. et al (Org.). Um olhar territorial para o desenvolvimento: Centro-Oeste. Biblioteca Digital - Banco Nacional de Desenvolvimento Econômico e Social. Rio de Janeiro-RJ, 512p. 2014. 
COSTA, H. C. et al. Espacialização e sazonalidade da precipitação pluviométrica do estado de Goiás e Distrito Federal. Revista Brasileira de Geografia Física. v.1, p.87-100, 2012.

CPTEC/INPE - Centro de Previsão de Tempo e Estudos Climáticos. Imagens de Satélite. 2015. Disponível em: <http://sinda.crn2.inpe.br/PCD>. Acesso em: jun 2015.

ESRI - ENVIRONMENTAL SYSTEMS RESEARCH INSTITUTE. ArcGIS mapping software, version 10.3. Conjunto de programas. Acessado em Jan-Dez 2018. Disponível em <https://www.esri.com/en-us/home>.

INMET Instituto Nacional de Meteorologia - Banco de Dados Meteorológicos para Ensino e 2015.2 Disponível em: <http://www.inmet.gov.br/portal/index.php?r=bdmep/bdmep >. Aceso em: jundez 2015.

LEROUX, M. Global Warming: myth or reality? The erring ways of climatology. Chichester, Praxis, 2005.

MARIANO, Z. F. A importância da variável climática na produtividade da soja no Sudoeste de Goiás. Tese (Doutorado em Geografia). Universidade Estadual Paulista Júlio de Mesquita Filho, UNESP. 2005.

MARINHA DO BRASIL. Centro de Hidrografia e Navegação. Serviço Meteorológico Marinho. Cartas de Pressão ao Nível do Mar. Acervo eletrônico de 1969-2016 (reservado).

MESQUITA, W. O. el al. Precipitações máximas diárias esperadas para as regiões central e sudoeste de Goiás. Pesquisa Agropecuária Tropical. v.39, n.2, p.73-81, 2009.

MICROSOFT OFFICE Project for Windows 2016, version 1801: project planning software. [S.I.]: Microsoft Corporation, 2016. Conjunto de programas. Acessado em: Jan-Dez 2018. Disponível em < https://products.office.com/pt-br/home>.

MONTEIRO, C. A. F. Notas para o estudo do clima do Centro Oeste Brasileiro. In: Rev. Brasileira de Geografia, n. 01. Rio de Janeiro, janeiro março. 1951.

MONTEIRO, C. A. F. Da necessidade de um caráter genético à classificação climática (algumas considerações metodológicas a propósito do estudo do Brasil Meridional). Revista Geográfica, Rio de Janeiro, v. 31, n. 57, p. 29-44. 1962.

MONTEIRO, C. A. F. Sobre a análise geográfica de sequências de cartas de tempo: pequeno ensaio metodológico sobre o estudo do clima no escopo da Geografia. Revista Geográfica, Rio de Janeiro, v. 31, n. 58, p. 169-179. 1963a.

MONTEIRO, C. A. F. O Clima da Região Sul. Geografia Regional do Brasil Região Sul. Rio de Janeiro, v. 1, p. 117-169. 1963b.

MONTEIRO, C. A. F. Sobre Um Índice de Participação das Massas de Ar e suas Possibilidades de Aplicação à Classificação Climática. Revista Geográfica; 61, Instituto Panamericano de Geografia e História, Rio de Janeiro, 1964.

MONTEIRO, C. A. F. Análise Rítmica em Climatologia - problemas da atualidade climática em São Paulo e achegas para um programa de trabalho. Climatologia 1, USP/IG, São Paulo, 1971. 
MONTEIRO, C. A. F. A Dinâmica Climática e as Chuvas no Estado de São Paulo: estudo geográfico sob a forma de atlas. USP/Igeog., São Paulo, 1973.

MONTEIRO, C. A. F. A Dinâmica Climática e as Chuvas no Estado de São Paulo. Rio Claro: UNESP, Ageteo, 2000. 1 CD-ROM.

NASCIMENTO, D. T. F.; OLIVEIRA, I. J.; LUIZ, G. C. Panorama dos sistemas de classificação climática e as diferentes tipologias climáticas referentes ao estado de Goiás e ao Distrito Federal (Brasil). Élisée - Revista de Geografia da UEG, v. 5, p. 59-86, 2017.

MONTEIRO, C. A. F.; NETO, J. M. S.; NUNES, L. C. Definição dos anos-padrão para o estudo da pluviometria do Estado de Goiás e do Distrito Federal. Brazilian Geographical Journal: Geosciences and Humanities research medium, Ituiutaba, v. 6, n. 1, p. 272-290, jan./jun. 2015.

NEVES, G. Z. F.; SPECIAN, V.; ROCHA, T.; VECCHIA, F. A. S. Síntese dos estudos climáticos e a distribuição da rede meteorológica no estado de Goiás e Distrito Federal. In: Archimedes Perez Filho; Raul Reis Amorim. (Org.). Os Desafios da Geografia Física na Fronteira do Conhecimento. 1ed.Campinas: Instituto de Geociências - UNICAMP, 2017, v. 1, p. 2378-2389.

NEVES, G. Z. F.; ALVES, E. D. L.; SPECIAN, V.; ROCHA, T.; VECCHIA, F. A. S. CARACTERÍSTICAS PLUVIOMÉTRICAS DO ESTADO DE GOIÁS E DISTRITO FEDERAL: considerações preliminares sobre o ritmo climático. In: Divino José Lemes de Oliveira; Washington Silva Alves; Thiago Rocha; Hyago Ernane Gonçalves Squiave; Daiane Ferreira Batista; Silvaci Gonçalves Santiano Rodrigues; Derick Martins Borges de Moura; Gustavo Zen de Figueiredo Neves. (Org.). Diversos olhares geográficos. 1ed.Goiânia: Kelps, 2017, v. 1, p. 38-53.

NEVES, G. Z. F. Distribuição geográfica das chuvas no Estado de Goiás e Distrito Federal: dinâmica e aplicações nos estudos rítmicos. 2018. Tese (Doutorado em Ciências - Engenharia Ambiental), Escola de Engenharia de São Carlos, Universidade de São Paulo, São Carlos-SP, 2018. DOI: 10.11606/T.18.2018.tde22052018-174146

PENEREIRO, J. C. et al. Identificação de tendências sazonais dos regimes climático e hidrológico na bacia hidrográfica dos rios Tocantins e Araguaia, Brasil. Revista Geografia Acadêmica. v.9, n.1, 2015.

QUADRO, M.F.L.; ABREU, M.L. Estudos de episódios de Zonas de Convergência do Atlântico Sul sobre a América do Sul. Anais II Congresso Brasileiro de Meteorologia, 8:620-623. Belo Horizonte-MG. 1994.

SANT'ANNA NETO, J. L. Ritmo Climático e a Gênese das Chuvas na Zona Costeira Paulista. Dissertação (mestrado) - Faculdadede Filosofia, Letras e Ciências Humanas, Universidade de São Paulo, São Paulo. 1990.

SEGPLAN. Secretaria de Estado de Gestão e Planejamento de Goiás. Instituto Mauro Borges de Estatísticas e Estudos Socioeconômicos. Atlas do Estado de Goiás. Goiânia: 98p. (2012). Acesso em 10.12.2015. Disponível em <http://www.sieg.go.gov.br/RGG/Atlas_IMB_2014/avulsos/1.6_Precipitacao_Plu viometrica_2012.pdf>.

STEINKE, E. T. Considerações sobre variabilidade e mudança climática no Distrito Federal, suas repercussões nos recursos hídricos e informação ao 
grande público. Tese (Doutorado em Ecologia), publicação ECO.TD, Departamento de Ecologia, Universidade de Brasília, Brasília-DF, 196p. 2004.

VIRGI, H., A preliminary study of summertime tropospheric circulation patterns overSouth America estimated from cloud wins. Mon. Weather Rev., 109, 549-610. 1981.

ZAVATTINI, J. A. A Dinâmica Atmosférica e a Distribuição das Chuvas no Mato Grosso do Sul. 1990. Tese (Doutorado em Geografia), Faculdade de Filosofia, Letras e Ciências Humanas, Universidade de São Paulo, São Paulo, 1990. 